\title{
«LO FATAL», UN POEMA CONCLUSIVO DE RUBÉN DARÍO
}

\author{
Francisco JaVier DíEZ DE REVEnGa \\ Universidad de Murcia
}

\section{Resumen}

La complejidad del mundo poético de Cantos de vida y esperanza, de Rubén Darío, es muy superior a la de sus libros anteriores, sobre todo porque se han intensificado de manera muy notable las reflexiones metafísicas que aparecen por todas partes y que se concentran en símbolos y referencias que, con una gran cohesión, aluden a preocupaciones muy claras del poeta, que resume y sintetiza en los poemas finales, y especialmente en «Lo fatal», el último poema del libro que se analiza en el presente trabajo.

Palabras clave: Rubén Darío, inmortalidad, destino, eros, tánatos, introspección.

\begin{abstract}
The complexity of the poetic world of Ruben Darío's Cantos de vida y esperanza is far superior to that of his previous books, especially since the metaphysical reflections that appear everywhere have intensified significantly and focus on symbols and references that, with great cohesion, refer to very clear concerns of the poet. These are summarized and synthesized in the final poems, and especially in «Lo fatal», the last poem in the book which is discussed in this paper.
\end{abstract}

Keywords: Ruben Darío, immortality, fate, Eros, Thanatos, introspection.

Uno de los avances más notables que se advierten en Cantos de vida y esperanza es la presencia del propio poeta en el libro, advertida desde el mismo comienzo, desde su poema prólogo, que, iniciado por el verso «Yo soy aquel que ayer no más decía», da nombre a todo el volumen. Adquiere esta composición la conformación genérica del «retrato», característico de la poesía 
modernista, en el que el poeta informa sobre sí mismo, sobre su vida pasada, sus anhelos, su programa de futuro, así como sobre su obra, la ya pasada y la rememora. El poema inicial inaugura un intenso programa de introspección, ya que es una especie de confesión general, a la altura de 1904, fecha de publicación en Alma Española. La melancolía, la tristeza y el abandono marcan el tono del poema que, sin embargo, se entusiasma con su autorretrato literario, como parte del género lírico, con detenida referencia a sus libros, a sus temas y motivos literarios, recorridos con una cierta complacencia (jardín de sueño, rosas, cisnes, tórtolas, lagos). Surgen los maestros, Hugo y Verlaine, cada uno desde su ángulo, y la ilusión, sobre todo la ilusión.

Naturalmente, en el autorretrato dariano, junto a la obra y los maestros, está el amor, el erotismo y la vida, la carne y el infierno, llega a decir el poeta, recordando su desordenada vida, que, a la altura de este 1904, quiere ya sosegar y tranquilizar. Por ello, tras la estatua alegórica y las imágenes eróticas plurales, están los buenos propósitos y el ansia de tranquilidad que ahora el poeta persigue como virtud tan necesaria para su espíritu.

Se viene atribuyendo a Cantos de vida y esperanza la condición de libro culminante en la trayectoria poética de Rubén Darío, así como en el mismo movimiento modernista. Rubén halla en este libro la medida exacta de su revolución poética, que supone la consolidación de los aires de innovación que comenzó en su libro Azul...Al mismo tiempo, se advierte una profundización en temas y motivos literarios con una notable tendencia hacia la introspección y reducción muy advertible de los aspectos más superficiales, preciosistas y convencionales del modernismo y de la propia poesía anterior de Darío. Hay en este libro más autenticidad, mayor intimismo y una presencia de asuntos más hondos y comprometidos llegando a expresiones llenas de dramatismo y estremecedoras.

La brillantez y el colorido de la poesía anterior, los grandes efectos orquestales, las representaciones fastuosas dan paso a una incipiente austeridad combinada con un cierto rigor en el tratamiento de algunos temas, que dejan traslucir un compromiso con temas más serios, tanto desde el punto de vista personal, como incluso social o político, en una vertiente que ahora se inicia, aunque tímidamente.

El signo de Cantos de vida y esperanza ahora es muy diferente, y son muchas las composiciones que, desde el prólogo poético ( «Yo soy aquel que ayer no más decía...»), nos introducen en una reflexión del pasado en el presente, con temor hacia el futuro, que será uno de los signos más valiosos e innovadores del libro de 1905. Como ha señalado Alberto Acereda, Cantos de vida y esperanza «recoge la mirada del poeta desde la mitad de la vida y se convierte 
así en una reflexión, en un balance que oscila entre el desasosiego dolorido y el descontento de sí mismo y del mundo y, por otro lado, una afirmación vital, apasionada porque el libro es contradictorio, polivalente...» (1992: 46) Reflejo, por tanto del propio poeta, obra maestra desde el punto de vista literario, artístico y estético, «es la imagen de un hombre que puede perderlo todo menos la vida y la esperanza, porque sabe muy bien que su destino final es la muerte» (1992: 46). Libro, por todo ello, capital en una trayectoria tan brillante como la de Rubén Darío, y definitivo en lo que a consolidación de las innovaciones aportadas por la revolución modernista se refiere, en especial en lo que atañe a profundización en el mundo interior y expresión de las angustias de un mundo personal que son las de toda una época y toda una generación.

En 1948, Pedro Salinas publica, en Buenos Aires, en la editorial argentina Losada, su libro La poesía de Rubén Darío. Ensayo sobre el tema y los temas del poeta. Como han señalado Enric Bou y Andrés Soria, en la introducción al volumen II de las Obras completas de Pedro Salinas, desde su aparición se convirtió en uno de los principales vehículos de introducción en el mundo del poeta nicaragüense para los lectores españoles y americanos. Es una pieza sobresaliente de un modo de crítica poco habitual en las tradiciones metodológicas españolas. Poco habitual porque su autor amplía el paradigma filológico-estilístico predominante entre sus coetáneos —incluidos los demás críticos poetas - con otros universos histórico-culturales, como la crítica temática de inspiración psicoanalítica, y porque se trata de un auténtico ensayo, donde sólo la escritura da voz al autor para preguntar por cuestiones vitales, una escritura cuya regla de oro es la «auctoritas personal» y el «constante autobiografiarse», y cuyo «designio» incluye no sólo la descripción abstracta de conclusiones, sino también «el proceso de su pensar» (2007: 40).

La complejidad del mundo poético de Cantos de vida y esperanza es desde luego, muy superior a la de los libros anteriores de Rubén Darío, sobre todo porque se han intensificado de manera muy notable las reflexiones metafísicas que aparecen por todas partes y se concentran en símbolos y referencias que, con una gran cohesión, aluden a preocupaciones muy claras del poeta, que resume y sintetiza en los poemas finales, y no sólo en «Lo fatal», como toda la crítica ha reconocido en Darío, que coloca en el último lugar del libro una especie de contrapunto o contrapeso respecto al primer poema «Yo soy aquel que ayer no más decía»:

Dichoso el árbol, que es apenas sensitivo,

y más la piedra dura porque ésa ya no siente,

pues no hay dolor más grande que el dolor de ser vivo

ni mayor pesadumbre que la vida consciente. 
Ser, y no saber nada, y ser sin rumbo cierto, y el temor de haber sido y un futuro terror... ¡Y el espanto seguro de estar mañana muerto, y sufrir por la vida y por la sombra y por

lo que no conocemos y apenas sospechamos, y la carne que tienta con sus frescos racimos, y la tumba que aguarda con sus fúnebres ramos y no saber adónde vamos, ni de dónde venimos...!

Pero, inmediatamente, antes, en el puesto anterior, situó el poeta su composición «Allá lejos», un poema de Cantos de vida y esperanza pocas veces recordado por los estudiosos, pero que parece fundamental en la construcción del mundo poético dariano, ya que contiene y expresa el sentimiento de la nostalgia, unido a la melancolía del recuerdo y al escepticismo de que lo pasado sólo es memoria.

Buey que vi en mi niñez echando vaho un día bajo el nicaragüense sol de encendidos oros, en la hacienda fecunda, plena de la armonía del trópico; paloma de los bosques sonoros del viento, de las hachas, de pájaros y toros salvajes, yo os saludo, pues sois la vida mía.

Pesado buey, tú evocas la dulce madrugada que llamaba a la ordeña de la vaca lechera, cuando era mi existencia toda blanca y rosada,

y tú, paloma arrulladora y montañera, significas en mi primavera pasada todo lo que hay en la divina Primavera.

Desde la distancia o lejanía en el espacio y en el tiempo, el poeta recuerda su patria y su niñez, que son evocadas en eglógica ruralidad con nostalgia intensa y nueva presencia animal de hondo significado: buey, paloma, pájaros, toros, ambiente familiar que supone para el poeta no ya la primavera que pasó, sino la eterna e inalcanzable, la que Rubén escribe con la inicial mayúscula, objeto de su ansiedad y de su amor: la divina Primavera. «Recuerdos tropicales», nos dice Rubén «de su tierra natal» (1919: 214), resumiendo poema y contenido. Salinas sí se ocupa de este poema en el contexto de la poesía social de Darío, y en concreto en relación con su sentimiento de «la nación», ya que él era ciudadano de muchas patrias, tal como estudia en un capítulo del libro, «Las patrias de Rubén Darío». El poema «Allá lejos» es, más que un poema de «nación», un poema de «nacimiento», ya que como otros poemas «nicaragüenses» de Darío, — «Momotombo»y «Tríptico»—, lo que contiene «son 
recuerdos, resurrecciones, idealizadas por el poeta, de ocurrencias sobrevenidas a su alma, a su propia intimidad, sin participación común.» El buey de la niñez — «buey que vi en mi niñez echando vaho un día / bajo el nicaragüense sol de encendidos oros»—, que figura en el poema, según Salinas, «significa en su dulce pesadez una etapa de la vida espiritual del poeta» (2007: 297).

Desde luego, el poema que mejor sintetiza el mundo poético de Cantos de vida y esperanza es «Lo fatal», una de las obras maestras del poeta no sólo de este libro sino de toda su trayectoria poética, como hemos señalado con anterioridad (2001: 39-40). La presencia de los reinos de la naturaleza, caracterizados por su insensibilidad (el vegetal, a través del símbolo del árbol, y el mineral, a través de la piedra, a los que el poeta envidia por no tener capacidad de sentir) abre un poema en el que Darío se interroga sobre el pasado, el presente o el futuro, muy en la línea del pensamiento angustiado de principios de siglo xx. Pero lo que angustia a Rubén es la ignorancia del destino, expresada entre tantas certezas. "Ciertamente —escribió Darío- en mí existe, desde los comienzos de mi vida, la profunda preocupación del fin de la existencia, el terror de lo ignorado, el pavor de la tumba, o, más bien, del instante en que cesa el corazón su ininterrumpida tarea y la vida desaparece de nuestro cuerpo» (1919: 214). La gran duda se produce entonces en el momento clave, cuando la religión no ha servido para aclarar lo que el poeta pregunta, aquello sobre lo que quiere saber y no sabe: «Ser, y no saber nada, y ser sin rumbo cierto, / y el temor de haber sido y un futuro terror... / Y el espanto seguro de estar mañana muerto, / y sufrir por la vida y por la sombra y por / lo que no conocemos y apenas sospechamos.»

Pero, en contraste, sí hay certezas, que constituyen las realidades que han pasado, su carnalidad y erotismo ( «la carne que tienta con sus frescos racimos») y lo que la experiencia nos dicta, y que sabemos por los que nos preceden, «la seguridad de estar muerto» («y la tumba que aguarda con sus fúnebres ramos»), contraste o antítesis que resume, a la manera barroca, toda una vida. Porque parece claro que la desolación no la produce la duda permanente, sino más bien la seguridad que esta recreación contemporánea del ubi sunt produce, tal como escribió Rubén en Historia de mis libros:

En «Lo fatal», contra mi arraigada religiosidad, y a pesar mío, se levanta como una sombra tenebrosa mi fantasía de desolación y de duda. Ciertamente, en mí existe, desde los comienzos de mi vida, la profunda preocupación del final de la existencia, el terror a lo ignorado, el pavor a la tumba [...] Todas las filosofías me han parecido impotentes, y algunas abominables y obras de locos y malhechores. En cambio, desde Marco Aurelio hasta Bergson, he saludado con gratitud a los que dan alas, tranquilidad, vuelo apacible y enseñan a comprender de la mejor manera posible el enigma de nuestra estancia sobre la tierra (1919: 214). 
Poema construido con una estructura formal muy cohesionada, basada en el ritmo del alejandrino, sólo interrumpido, al final por un eneasílabo para contener la cláusula exclamativa que concluye el poema, rematada con la vuelta al ritmo alejandrino (en realidad el primer hemistiquio heptasílabo), como si quisiera volver a empezar. Amado Alonso ya destacó «el retorno al pasaje alejandrino en el último verso no hace más que resaltar el valor expresivo de esa ruptura momentánea del ritmo» (1965: 330).

Salinas incluye en su libro un espléndido comentario sobre este poema, como es lógico, dado que es uno de los más representativos de todo Darío. Lo considera «la altísima queja de una de sus más hermosas poesías» (2007: 758), pero, más aún, lo valora como «la queja contra la gran culpable» (2007: 758), y le vale su comentario para efectuar una consideración, interesante desde el punto de vista teórico, sobre si un poema tiene autonomía o no o debe considerarse como parte de un conjunto. Una referencia oportuna a T. S. Eliot, «en uno de sus últimos ensayos — "What is a minor poet" — tocaba el tema de la inseparabilidad, dentro de la obra de un poeta, de todas sus poesías, y de la ayuda que presta a la total inteligencia de una de ellas el conocimiento de las demás» (2007: 759), le abre el camino para la consideración del poema como ente autónomo pero también en conjunto con toda la obra del poeta:

Aunque «Lo fatal» es poema de completa autonomía de sentido, creo que sólo cobra toda su altitud de significación cuando se le mira a la luz de las poesías más exaltadas de la fase erótica pura. Si se acepta la idea de Amado Alonso de que en estos cuatro versos hay una escala (piedra, que no siente; árbol, que es apenas sensible; animal, vivo pero sin plena conciencia; y hombre, poseedor único de la vida consciente), veremos que lo que envidia el poeta a los tres primeros términos de esa escala es lo que no tienen, es un no tener. Son dichosos piedra, árbol y animal porque carecen de sentidos, de sentimiento, de conciencia, todo ello posesión y tesoro del hombre. Tal pesimismo representa la dimisión del ser humano del alto rango donde se le ha venido poniendo siglos y siglos, precisamente por ser dueño de las facultades de sentir y pensar. La dignidad del hombre, concepto ganado tan esforzadamente por el homo sapiens, cede el paso, derrotada, a las fuerzas prerracionales, oscuras — fatalidad y terror- del mundo mágico del primitivismo, del homo sylvanus. La confianza que da a la razón se pierde, y el hombre retorna al espanto de lo aún no construido en la mente, de lo caótico. Todo esto vale por sí, y «Lo fatal» es organismo poético perfecto. Pero ¡cómo se intensifica, se dramatiza su significado, si se mira al poeta de este momento, junto a aquel que ponía su vida entera al servicio de la sensibilidad, cuando refinaba exquisitamente su arte de sentir, y les convertía en variado teclado del que se pudiera sacar los matices sutiles y las notas triunfales! Entonces el mundo exterior existe, como para su maestro Gautier, y el hombre se entrega a todos los primores y sabidurías de que sean capaces sus ojos, sus manos, su boca, sus oídos, en el disfrute de las realidades (2007: 759). 
Salinas se está refiriendo ahora exclusivamente a cuatro versos del poema: «Dichoso el árbol, que es apenas sensitivo, / y más la piedra dura porque esa ya no siente, / pues no hay dolor más grande que el dolor de ser vivo, / ni mayor pesadumbre que la vida consciente». Para señalar que, en ellos,

la vida se exalta triunfalmente tal y como la brindan generosamente los sentidos, que se pasean por sus extensiones como abejas buscadoras, posándose en las más bellas formas y sacándoles su dulzor. Ahora, en la estación del huracán el poeta maldice los sentidos, los que le hacían feliz. Abomina de la vida en la que se ardía complacido; la llama supremo dolor. Derrumbamiento patético, por obra de tres versos, de todo un mundo, el mundo de lo sensual, tan suyo, tan patrio, que no podrá salir de él mientras viva. El cuarto verso de la estrofa descubre a la autora de semejante cataclismo; no es otra que la vida consciente, la conciencia, la reveladora del tiempo que, con esa revelación, desencadena la catástrofe. La conciencia es la mayor pesadumbre; porque su peso, al gravitar sobre las levísimas estructuras de aquella ciudad pintoresca y abigarrada de los sentidos, con su población de faunos, marquesas, ninfas y cisnes, la hace venirse a tierra; que queda sembrada de tristísimos restos, recuerdos desengañados. «Lo fatal» no se siente hasta el fondo, mientras no se vea todo el estrago que hace en los demás poemas, en la concepción erótica del poeta, en el otro. Porque el ser dual renueva su salida en los últimos versos del poema, en dos versos donde queda desgarrada la unidad, la felicidad del hombre, puesto que tiran de él, cada uno por su opuesto impulso; versos literalmente desgarradores: "Y la carne que tienta con sus frescos racimos, / y la tumba que aguarda con sus fúnebres ramos ...» (2007: 759).

La conclusión de Salinas es que todo esto tiene mucho que ver con el resto de la obra, y, desde luego, con el tema del poeta, el tema principal, que es lo erótico, aunque ahora sea desde una perspectiva final, agónica, en la que los elementos están llevados a un extremo sin retorno. Y así lo concluye el gran poeta y crítico:

Eso es lo fatal. Que no puede deshacerse el poeta de su erotismo. Sigue estando aquí. En esta calígine, en la fosquedad de los «Nocturnos», lo erótico persiste, como tema. También la tierra, con sus plantas, sus cielos y sus animalias, es el tema de la noche, igual que lo ha sido antes del día. La oscuridad modela en ella sus bultos misteriosos, como la luz sus imágenes radiosas. Nada entre la lobreguez nocturna asemeja a lo que vemos de día; el soto se aborrasca en negrura y se finge masa impenetrable y hostil. La estatua de mármol, en los jardines, es tenebroso espantajo que va a caer sobre nosotros, aterrorizados. Todo es otro. Y, sin embargo, todo sigue siendo lo mismo. Así, en los poemas de la conciencia de Rubén la obsesión erótica es tan presente como en los demás. Lo que ha sucedido es que antes lo erótico estaba confinado en sí mismo: era valor absoluto, alumbrado de su propia luz, tan poderosa que cegaba para lo restante. $\mathrm{Y}$ ahora el poeta empieza a percibir las innumerables relaciones de lo erótico con el resto del mundo; siente, sobre 
todo, la dependencia de lo erótico de algo que no es él, que está fuera de él. Empieza a vivir más, porque vive más quien mayor número percibe de estas maravillosas dependencias de las realidades (2007: 760).

Recuerda en su edición de Cantos de vida y esperanza José Carlos Rovira unas palabras del poeta Ángel González de 2003, que no nos resistimos a reproducir: «"Lo fatal" trata de la incertidumbre de la existencia, del radical desamparo de los seres humanos perdidos en el tiempo con un solo punto de referencia: la inevitabilidad de la muerte: lo demás es misterio impenetrable» (2004: 246).

No se conoce ninguna publicación previa de este poema. Por lo que podemos pensar que Rubén lo escribe precisamente para cerrar Cantos de vida y esperanza, lo que no ocurre con otros muchos poemas del libro que fueron publicados previamente. No puede pasar inadvertida la situación del poema en el libro. Es el que lo cierra y por ello se establece un contraste con el poema que lo abre, el retrato al que nos hemos referido antes, "Yo soy aquel que ayer no más decía». Por su situación en el libro lo hemos denominado poema conclusivo. Y también es importante en este sentido el propio título, en neutro del poema «lo fatal». El título, «Lo fatal», alude a la angustia que experimenta el yo poético ante la existencia y lo ineludible de la muerte («el espanto seguro de estar mañana muerto»); la condición consciente del ser humano que no puede evitar el sufrimiento que produce esta certeza ( «no hay dolor más grande que el dolor de ser vivo / ni mayor pesadumbre que la vida consciente»).

Hay otros aspectos externos muy interesantes en relación con «Lo fatal» que no pueden ser obviados cuando del poema tratamos. Por ejemplo el dedicatario. La dedicatoria, en todas las ediciones, reza: «A René Pérez». Se trata, como recuerda José Carlos Rovira (2004: 245) de un amigo de Rubén, de París y chileno de nacimiento, René Pérez Mascayano: hombre de negocios, pianista y compositor. En 1905 coincide con él en París y lo visita en su pisito de la calle Feydeau, 26, acompañado de otro chileno, Francisco Contreras. Es cuando Pérez Mascayano lo anima a volver a Chile tirado por un cisne, como Lohengrin. «No es país de cisnes ése, respondió sordamente [el poeta], recordando sin duda ciertos ataques que allí, hacía poco, le hicieran». Como anota en su edición de Cantos de vida y esperanza José Carlos Rovira, en los días parisinos coincidió con Rubén Darío y asistió a la fiesta familiar del bautizo de Guicho, el hijo de Rubén y de la española Francisca Sánchez, en octubre de 1907 (2004: 245).

El mismo Pérez Mascayano escribió a Rubén en diversas ocasiones cartas que se conservan y Pérez Mascayano fue secretario de Rubén Darío, desde su primer número (mayo, 1911), en la revista Mundial, en la que figura junto 
al director artístico Leo Marello. pero antes colaboró con Darío en la correspondencia previa, ayudado por René Pérez, se escribió cartas a sus amigos de España y América, escritores, publicistas o magnates aficionados a las letras pidiéndoles colaboración.

También hay que hacer algunas referencias de carácter estilístico, que nos permiten conocer el mundo retórico y estético de este Rubén de 1905. Por ejemplo, la estructura externa que no es sino la de un soneto alejandrino modificado o frustrado. De la trascendencia en la recuperación del alejandrino y del papel de Darío en su difusión ya traté hace muchos años (1985: 13-55) y no es extraño que el poeta utilizase una vez más el verso de catorce sílabas para un poema tan significativo que se estructura sobre tres estrofas cuya rima es consonante en todo el poema, y la distribución de sus rimas es alterna como corresponde al serventesio (ABAB - CDCD - EFEEF). Pero los dos últimos versos presentan una irregularidad: en lugar de ser un alejandrino, como en las estrofas anteriores, se fragmenta en dos versos, 1 eneasílabo (9 sílabas) y 1 heptasílabo ( 7 sílabas) dando lugar a un serventesio truncado con la eliminación del verso del último terceto, decisión que puede relacionarse con la intención de Rubén Darío de romper la estructura tradicional del soneto y así reflejar la fatalidad del asunto que está tratando. Los verbos, adjetivos y sustantivos pertenecen a los campos semánticos del miedo, del sufrimiento, de la vida o de la muerte. Los sustantivos abstractos dominan la primera parte del poema y los verbos están en presente para otorgar sentido absoluto y permanente al poema. Los infinitivos muestran firmeza expresiva y sentenciosa. Los campos semánticos de la muerte (muerte, tumba, fúnebre) y la vida (ser vivo, vida) provocan las antítesis fuertemente convincentes. Vida y muerte se enlazan a lo largo de todo el poema en el campo de las sensaciones y el sentimiento.

Es interesante la estructura retórica interna del poema con la presencia de numerosos recursos estilísticos que refuerzan la expresión de su contenido. Así la gradación señalada tantas veces: La piedra («no siente») el árbol («apenas sensitivo») el hombre («sensitivo y consciente»). Así, todos los seres vivos, excepto el hombre, son dichosos al vivir en la inconsciencia. El hecho de ser consciente, es decir, su capacidad de reflexión sobre el destino o el azar y el sentido de la vida, supone el mayor dolor. También hay una enumeración de los males que suponen el vivir y que provocan la angustia existencial, siendo el peor la certeza de la muerte. Los reinos mineral, vegetal, animal y animal racional son la estructura ideológica sobre la que se basa la afirmación dariana de que el que peor lo tiene, el que sale perdiendo, es el reino animal racional: el ser humano. 
Hay algunos rasgos reiterativos que nos descubren al mejor Rubén: el de los efectos acústicos más expresivos. Desde la aliteración, como en el verso: Ser, y no saber nada, y ser sin rumbo cierto, al destacadísimo polisíndeton reiterado por cuyo efecto cada elemento de la enumeración se coordina con la conjunción copulativa y más el siguiente elemento y así se logra la sensación de que la angustia del poeta va en aumento. La antítesis (por la vida-por la sombra / sensitivo-ya no siente / frescos racimos-fúnebres ramos / adónde vamos-de dónde venimos), una gradación ascendente de términos que significan miedo o angustia (temor, terror, espanto) y que abarcan los tres tiempos: presente (ser sin rumbo cierto), pasado (el temor de haber sido) y futuro (un futuro terror) lo que supone una angustia dolorosa, las abundantes las metáforas (la carne que tienta con sus frescos racimos) y las hipérboles (no hay dolor más grande que el dolor de ser vivo, el espanto seguro de estar mañana muerto) remiten constantemente a la vida y la muerte reiterando continuamente en estas ideas. Se observa también que en las dos últimas estrofas hay una anáfora con la repetición de la conjunción y al principio de los versos para remarcar más la idea de incertidumbre y desconocimiento, como una letanía.

Debemos reparar igualmente en los catorce verbos que contiene el poema: ser — dos veces—, saber — dos—, sentir, haber, estar, sufrir, conocer, sospechar, tentar, aguardar, ir y venir. También hay que reparar en los quince sustantivos (vida — dos veces_- dolor —otras dos_, árbol, piedra, pesadumbre, rumbo, temor, terror, espanto, sombra, carne, racimos, tumba y ramos). Pero sobre todo hemos de aludir a las diez veces que aparece la conjunción copulativa «y». Es muy interesante también desde el punto de vista estilístico el funcionamiento del encabalgamiento en el verso 9: lo que no conocemos y apenas sospechamos.

Comentario aparte merecen la estructura fonética, morfológica, sintáctica y semántica de los versos 10 y 11 , en los que se produce una inquietante correlación: reproducción idéntica de fonética, morfología, sintaxis para producir un contraste fortísimo dese el punto de vista semántico: «y la carne que tienta con sus frescos racimos / y la tumba que aguarda con sus fúnebres ramos».

Los recursos expresivos de que se vale el poeta para poner de manifiesto esta oposición son fundamentalmente el paralelismo: (la (artículo determinado) carne (sustantivo-antecedente) que tienta (subordinada adjetiva de relativo) con sus frescos racimos (complemento circunstancial) frente a la (artículo determinado) tumba (sustantivo-antecedente) que aguarda (subordinada adjetiva de relativo) con sus fúnebres ramos (complemento circunstancial). La 
metáfora (frescos racimos representa a la vida, fúnebres ramos representa a la muerte) y la antítesis que se da entre los dos hemistiquios de cada verso que hacen referencia a la vida y la muerte. Eros y tánatos como contraste representativo de toda la existencia del propio poeta: pasado y futuro enfrentados en una misma estructura estilística.

Uno de los aspectos que ha suscitado en la crítica especializada especial interés ha sido la averiguación de las fuentes de este poema de Rubén Darío. Se trataría entonces, a la hora de comentar este texto, de entrar en el campo de la que Pedro Salinas denominaba la «crítica hidráulica» (1974: 103), es decir la localización de las fuentes en las que el poeta bebió.

En el artículo antes citado de Amado Alonso, aludía el maestro de filólogos a la relación de los símbolos utilizados por Rubén Darío con un soneto de Miguel Ángel, aunque reconoce que los versos que pudieron inspirar a Rubén «son solo el primero y el tercero: la progresión «sueño-piedra» ha sido cambiada en «árbol-piedra». La «gran ventura de no ver ni sentir» es lo que Rubén envidia» (1965: 331):

Caro m'è'l sonno e più l'esser di sasso,

Mentre ch'el danno e la vergogna dura.

Non veder, non sentir m'è gran ventura;

Però non mi destar, deh! parla basso.

Aunque reconoce que «El sentimiento poetizado en "Lo fatal. no se lo prestó nadie. Era en él obsesionante, y según confidencias de amigos, que aprovechan enemigos, su miedo a la muerte llegó a ser morboso» (1965: 333).

Arturo Marasso aludió a la escala de sensibilidad reflejada por: piedraárbol-animal-hombre, expuesta por el científico francés Claude Bernard en su obra La Science Expérimentale (La ciencia experimental) (1878). Rubén sublima un asunto e incluso un vocabulario científico y los convierte en poéticos. Marasso fue el que estableció la fuente principal de este soneto frustrado en la relación entre tal escala de sensibilidad y el poema de Darío: la piedra dura (esa que no siente), el árbol (es apenas sensitivo), el dolor de ser vivo (sin entera conciencia, vida animal) y la vida consciente (el hombre). «El continuo paralelismo de las imágenes de Darío con las ideas de Claude Bernard me induce a pensar que nuestro poeta ha escrito "Lo fatal" después de leer el libro del sabio francés» (1954: 281).

Sin embargo a Rubén Benítez ni la relación con Miguel Ángel ni la dependencia de Claude Bernard le parecen muy sólidas: «El tono humorístico del soneto de Miguel Ángel y el frio acercamiento científico de Bernard nada tienen que ver con la profunda emotividad de esta poesía. Con respecto a Bernard, lo único que sobrevive en un análisis crítico, como posible influencia, 
es el ordenamiento de los seres vivos de acuerdo con la sensibilidad. Ordenamiento tan frecuente en textos clásicos y modernos que su enumeración fatigaría» (1972: 509).

Y es que Rubén Benítez estudió con detalle la relación de este poema con Arthur Schopenahuer y la concretó al localizar en el capítulo 56 de Welt als Wille und Worstellung (El mundo como voluntad y representación) (1819), la conexión de la filosofía del pensador alemán con este poema especialmente y señala que "Lo fatal" está impregnado de pesimismo, de "desolaci6n y de duda". Para un hombre de la generación de Darío, el pesimismo no necesita remontarse a etapas del Renacimiento ni a la ciencia experimental. Tiene la más cercana formulación - y la mejor- en Schopenhauer», de quien recuerda el siguiente y muy expresivo fragmento (1972: 512):

Pues a medida que el fenómeno de la voluntad se hace más perfecto, el dolor se hace también más evidente. En la planta no hay todavía sensibilidad, ni por consiguiente, dolor (en sentido estricto). Los animales inferiores, infusorios y radiarios, no son capaces más que de un grado mínimo de dolor; hasta en los insectos, la facultad de sentir y de padecer es todavía muy limitada. Con el perfecto sistema nervioso de los vertebrados llega a gran altura y se eleva en la proporción en que se desenvuelve su inteligencia. A medida que el conocimiento se hace más claro y que la conciencia crece, el dolor aumenta, y llega a su grado supremo en el hombre. En el es tanto más violento cuanto más lucidez de conocimiento y más elevada inteligencia posee. El genio es quien más padece.

Indudablemente, algo había cambiado en Rubén Darío a la altura de 1905 cuando se decide a cerrar Cantos de vida y esperanza, Los cisnes y otros poemas con este poema conclusivo, que se relaciona con el pensamiento filosófico y literario que alimentó la crisis espiritual de comienzos del siglo xx cuando tantos pensadores se preguntaron por el destino y por la inmortalidad. En la España de 1905 el pensamiento de Rubén nada desentonaba de la aguda crisis espiritual que alimentó a Unamuno, a Azorín, a Baroja y a Antonio Machado. Entre todos marcaron el rumbo de lo que habría de ser la literatura española del siglo Xx, una literatura comprometida con el ser humano y su destino más allá de dogmatismos y creencias arraigadas.

\section{Bibliografía citada}

ACEREDA, Alberto, Rubén Darío, poeta trágico (Una nueva visión), Barcelona, Teide, 1992.

ALONSO, Amado, «Estilística de las fuentes literarias: Rubén Darío y Miguel Ángel», Materia y forma en poesía, Madrid, Gredos, 3ª edición, 1965. 
BENíTEZ, Rubén, «Schopenahauer en "Lo fatal" de Rubén Darío», Revista Iberoamericana, 38 (1972), pp. 507-512.

DARío, Rubén, Cantos de vida y esperanza, los cisnes y otros poemas, edición de Francisco Javier Díez de Revenga, Salamanca, Almar, 2001.

- Cantos de vida y esperanza, Los cisnes y otros poemas, Edición prólogo y comentario de José Carlos Rovira, Madrid, Alianza, 2004.

- El viaje a Nicaragua e Historia de mis libros, Obras completas, vol XVII, Madrid, Mundo Latino, 1919.

DíEZ DE ReVEnGA, Francisco Javier, Rubén Darío en la métrica española y otros ensayos, Murcia, Departamento de Literatura Hispanoamericana, Universidad de Murcia, 1985.

MARAsSo, Arturo, Rubén Darío y su creación poética, Buenos Aires, Kapelusz, 1954.

SAlinas, Pedro, La poesía de Rubén Darío. Ensayo sobre el tema y los temas del poeta, Buenos Aires, Losada, 1948.

- Jorge Manrique o tradición y originalidad, Barcelona, Seix Barral, 1974.

- Obras completas, Ensayos completos, edición de Enric Bou y Andrés Soria, Madrid, Cátedra, 2007. 